\title{
PREFACIO DE LAS EDITORAS: ORALIDAD Y ESCRITURA LITERARIA
}

\author{
Silvia IgLesias ReCuero \\ Universidad de Salamanca \\ Araceli LóPEZ SERENA \\ Universidad de Sevilla
}

Antes de su inesperado fallecimiento, el 10 de noviembre de 2017, José Jesús de Bustos Tovar se había comprometido a dirigir un número monográfico sobre oralidad y escritura literaria para la revista Oralia. Tras su triste desaparición, su gran amigo Antonio Narbona nos pidió a quienes finalmente figuramos como coordinadoras del presente volumen que asumiéramos el reto de no dejar este encargo en saco roto. Dado que ambas habíamos explorado la recreación literaria de lo oral en nuestras tesis doctorales, dirigidas, precisamente, por Jesús Bustos y por Antonio Narbona, respectivamente, y dados el afecto y la admiración que las dos teníamos por la figura del profesor Bustos, aceptamos sin dudarlo la encomienda, con dos únicas condiciones: poder dedicar este número a la memoria de nuestro añorado Jesús y contar, para su publicación, con un prólogo del propio profesor Narbona. En este prólogo, que su autor ha querido titular «Una tarea fascinante», en sintonía con lo ya expresado hace años por nuestro también añorado Wulf Oesterreicher, afirma A. Narbona «que la búsqueda de huellas y vestigios de la [oralidad] en la [escritura o escrituralidad] constitu[ye] la tarea más fascinante para un lingüista o historiador de la lengua». Efectivamente, como señala Santiago del Rey Quesada en su contribución a este homenaje, «la fascinación que algunos investigadores [...] han sentido por descubrir huellas de la oralidad [...] en textos antiguos [...] tiene probablemente que ver con el carácter "mágico" que Johannes Kabatek atribuye a este campo de investigación». En su opinión, «intentar hallar elementos de la conversación real en textos antiguos convierte al lingüista en una especie de arqueólogo que se embarca en una aventura tan gratificante como arriesgada», debida, en muchos casos, como también afirma S. del Rey, «a la lectura de numerosos trabajos de José Jesús de Bustos Tovar».

En la introducción a su artículo para este volumen, este mismo investigador establece una distinción, en el ámbito de los estudios que abordan la 
presencia de lo oral en lo escrito en el campo de la historia de la lengua, entre dos tipos de aproximaciones: aquellas «que se centran en documentos que, bien por la naturaleza sociolingüística del emisor, bien por la naturaleza discursiva del texto, incorporan [...] rasgos "auténticos" asociados a la inmediatez comunicativa (cartas particulares, actas inquisitoriales, documentos jurídico-administrativos de diversa índole, etc.» y aquellas que analizan «obras literarias pertenecientes a géneros (diálogo, teatro, novela, etc.) en los que se produce una mímesis de la oralidad intencionada». El presente número monográfico, cuyas contribuciones se han dispuesto por estricto orden alfabético de acuerdo con los apellidos de sus autores, se inscribe, claramente, en el segundo de estos grupos, cuyo común denominador es el examen de la especificidad de los productos lingüísticos derivados de «una (re)elaboración consciente» de lo hablado conversacional que se desarrolla en el marco de «diferentes constelaciones estilísticas y retóricas dependiendo de la época y del autor», y en la que, tal como destaca Del Rey, «es fundamental la vocación de crear verosimilitud».

Así, el trabajo de Marta Albelda, titulado «La atenuación como signo de madurez dialógica en la conversación entre don Quijote y Sancho Panza», analiza el comportamiento del fenómeno de la atenuación pragmática en el Quijote. Con el objeto de «respaldar la tesis de la madurez dialógica» de la primera novela moderna, su autora pone de relieve la escasa presencia de mecanismos atenuativos en cuatro obras que ya Jesús Bustos había examinado desde el punto de vista de la recreación literaria de la lengua hablada, El Corbacho (1438), La Celestina (1499), La lozana andaluza (1528) y Lazarillo de Tormes (1554). Frente a los datos que arroja la novela cervantina, Albelda explica «el exiguo recurso a la atenuación en tales obras de transición» por «la limitada fluidez interactiva» y la «organización conversacional» «rígida y artificial» que constata en ellas, así como por la presencia absolutamente predominante, en sus diálogos, de la transmisión de contenidos, en detrimento de la construcción de relaciones sociales o de la expresión de actitudes personales. En su opinión, las manifestaciones de la atenuación que sí halla en las intervenciones de caballero y escudero de la obra de Cervantes están relacionadas con la importancia, en los intercambios conversacionales entre ambos personajes, del mantenimiento de una adecuada relación interpersonal, mediante la modulación de las posibles amenazas al territorio o la imagen del interlocutor que pudieran suponer determinadas peticiones, rechazos, desacuerdos o exposición de enseñanzas. En concreto, Albelda analiza el capítulo Xv de la obra e identifica, «por un lado, mecanismos de reducción directa de la fuerza ilocutiva (atenuantes pragmáticos o atenuación del modus, de acuerdo con Briz 1998) y, por otro lado, una serie de atenuantes del contenido proposicional, que reducen secundariamente la fuerza ilocutiva (atenuantes semántico-pragmáticos o atenuación del dictum, 
de acuerdo con Briz 1998)». Entre estos últimos, destacan el empleo de eufemismos, el uso adverbial de algo con valor indefinido, la fórmula como que y la litote. Entre los primeros, se cuentan los acotadores de la opinión del hablante («a lo que yo veo»), la aparición de adverbios como quizá y de verbos epistémicos débiles (parecer) que minimizan la fuerza ilocutiva de las aserciones, justificaciones de la emisión de peticiones mediante verbo dicendi seguido de subordinada causal, la mitigación de estas mismas peticiones mediante el uso del condicional de querer, de construcciones condicionales del tipo «si fuera posible»o de fórmulas impersonales de atenuación de necesidad deóntica como «conviene que», así como la expresión indirecta de respuestas negativas despreferidas mediante preguntas retóricas. De entre todos estos procedimientos, Albelda considera como mecanismo de atenuación especialmente característico de esta novela el recurso a apelaciones al conocimiento del que el interlocutor precisa disponer, mediante fórmulas, puestas normalmente en boca de don Quijote, como «sábete, amigo Sancho» o "porque quiero hacerte sabidor, Sancho», con las que se evita presentar una determinada información o un consejo directamente.

Uno de los aspectos menos atendidos hasta el momento en los estudios de la oralidad fingida o mímesis literaria de la oralidad -con excepciones notables, no obstante, como Narbona (1997 y 2015), López Serena (2007) entre otros- es el de su sintaxis. A ello se aplica Margarita Borreguero en su trabajo «El valor adversativo de aunque, un rasgo de la oralidad mimética»-en el que se resuelven las referencias bibliográficas que se acaban de citar-, y en el que compara y analiza el funcionamiento de esta conjunción en ejemplos extraídos de corpus orales (Corpes XXI y C-Or-DiAL) y en dos novelas, muy distintas, pero reconocidas por su acercamiento lingüístico y discursivo a la variedad conversacional: Historias del Kronen de José Ángel Mañas y Nubosidad variable de Carmen Martín Gaite. Tras un apartado de reflexión sobre la «mímesis de la oralidad y la sintaxis coloquial», en el que revisa los planteamientos teóricos y los estudios realizados sobre esta relación hasta el momento, la autora pasa a caracterizar las propiedades prosódicas, sintácticas, semánticas y discursivas de los usos de aunque como conector adversativo. Estos usos, que revelan su autonomía sintáctica, son -a diferencia de su empleo como conjunción concesiva- mucho más frecuentes en la construcción oral del discurso. Seguramente por este motivo han quedado hasta cierto punto relegados en los estudios sobre la conexión discursiva. En este sentido, Borreguero distingue entre los valores como conector contrargumentativo restrictivo, refutativo y rectificativo de aunque, siendo estos dos últimos los más característicos de la ausencia de planificación propia de la «andadura sintáctica» de la oralidad coloquial. Tras esta caracterización, realizada a partir de ejemplos extraídos de corpus orales, se analiza su uso en el discurso de los personajes de las dos novelas citadas 
y se muestra cómo funciona como elemento «evocador de la oralidad». Finaliza el artículo abogando -en la línea de los trabajos de Antonio Narbona y Araceli López Serena- por una mayor atención a la sintaxis de la oralidad, mediante análisis cuantitativos y cualitativos que reflejen los procesos de construcción del discurso en situaciones de inmediatez comunicativa y que permitan, en consecuencia, un acercamiento progresivamente más sólido a su estudio en el ámbito de la mímesis literaria de la oralidad.

Desde la perspectiva traductológica, Jenny Brumme aborda en «Lengua viva en la traducción. Variedades y acentos en un modelo integrado: A propósito de Águilas y ángeles de Juli Zeh» la discutida cuestión de cómo adaptar en el texto meta (TM) rasgos pertenecientes a los distintos eslabones de la cadena de variedades (Koch y Oesterreicher 1985, 1990[2007]) que se emplean en el texto fuente (TF) para caracterizar el habla de los personajes $-\mathrm{y}$, consecuentemente, por su valor sintomático- a los personajes mismos en las narraciones literarias. El trabajo de Brumme parte de la constatación de los problemas de traducción que plantean la distinta configuración variacional entre lengua fuente y lengua meta y las asociaciones socioculturales vinculadas a tales configuraciones y que desaconsejan una adaptación automática o ingenua de una a otra (por ejemplo, «traducir» rasgos del dialecto bávaro por rasgos del andaluz), y obligan, por el contrario, a una (re-)elaboración reflexiva de la «oralidad fingida» del TF en busca de la naturalidad en la evocación del habla conversacional. Para tal (re-)elaboración, el traductor puede optar por una gama de técnicas que Brumme organiza a partir de la propuesta de Marco (2002: 81) y el modelo de la cadena de variedades de Koch y Oesterreicher citado supra (incluyendo la dimensión diamésica o diamedial para las lenguas que la han desarrollado), y que abarcan desde el empleo de la lengua estándar y el mantenimiento o reforzamiento de los rasgos universales-genéricos del discurso prototípico de la inmediatez comunicativa (alternancia de turnos, marcadores discursivos, modalidad) al empleo de rasgos históricos-idiomáticos (fónicos, léxicos o sintácticos) propios de las variedades diastráticas, diafásicas (o diamésicas) de la lengua meta susceptibles de aparición en la interacción conversacional coloquial. A la luz de este marco teórico, esta autora analiza cómo se emplean tales técnicas a través de una comparación entre las distintas traducciones al español, catalán, inglés y francés de pasajes dialogados -en estilo directo- de la novela alemana Águilas y ángeles.

También desde una perspectiva parcialmente traductológica, aunque la traducción no sea su principal objeto de interés, en «Variantes de la oralidad elaborada en la segunda mitad del siglo XIX: dos traducciones coetáneas de Los cautivos de Plauto», Santiago del Rey Quesada, a cuyo trabajo se hizo ya alusión anteriormente, introduce el concepto de oralidad elaborada para llamar la atención sobre el perfil concepcional específico que manifiestan 
las estrategias de oralización en la literatura. Frente al interés prácticamente exclusivo que, en el ámbito de la mímesis de lo oral en la literatura, se ha prestado a la recreación de la lengua hablada coloquial, Del Rey apuesta por atender también a la mímesis conversacional de interacciones formales. A su modo de ver, la oralidad elaborada, de la que forman parte «fenómenos concepcionalmente heterogéneos» entre los que se incluyen estrategias sintácticas y discursivas alejadas de la inmediatez comunicativa como la presencia de elementos formulaicos en el inicio de turno, de expresiones de aceptación argumentativa y marcadores conversacionales del tipo es verdad que, así es, está(i)s en lo cierto, decís/dices verdad, etc., así como «elementos que imponen a la escritura dialógica un carácter impostado y retórico» revelador de un determinado ideal de estilo, «se erige en modelo de lengua conversacional en el primer Renacimiento (cf. Del Rey 2015a) y [tiene] una vigencia férrea en diversos géneros literarios de la literatura hispánica hasta bien entrado el siglo XX». En su trabajo, se analizan las versiones españolas de la obra Captivi de Plauto que llevaron a cabo Marcelino Menéndez Pelayo y Antonio González Garbín a finales del siglo xix, aunque haciendo abstracción de todo lo que concierne al propio proceso de traducción y concentrándose en la comparación de los dos textos meta en busca de datos de variación concepcional intraidiomática referidos a fenómenos como la presencia de interrogativas y exclamativas eco que dan lugar a figuras de escalera, el uso del conector explicativo es que o de pero seguido de la conjunción si no condicional con valor replicativo, el recurso al infinitivo por imperativo en la versión de González Garbín, la presencia de tópicos y focos en el margen izquierdo del enunciado, la utilización de las perífrasis de relativo que comúnmente se conocen como oraciones «hendidas», incluido el empleo de lo que es topicalizador, o la eclosión de la interjección ¡bah! en el diálogo novecentista. A partir de este muestreo, Del Rey llega a la conclusión de que en la mímesis conversacional decimonónica «existen elementos en los textos analizados cuya presencia recuerda a la que se constata en los escritores de diálogos y en los dramaturgos áureos: construcción del discurso a base de la repetición de verbos de lengua y percepción, abundancia de diferentes tipos de interrogativas marcadas, fórmulas conversacionales de diverso tipo -incluidas las preguntas con perífrasis de relativo-, explotación del margen izquierdo del enunciado en el inicio de turno, variedad de interjecciones adscribibles a un variado espectro variacional, etc. Sin embargo, aparecen innovaciones significativas, tanto cualitativas como cuantitativas, que nos permiten hablar de un nuevo capítulo de la oralidad elaborada en la literatura española».

La importancia de estudiar el impacto sociocultural que tuvo la incorporación de la escritura y de las tradiciones discursivas que ella implica en sociedades originariamente orales como la peruana de los siglos XVI y XVII 
es el tema que propone Carlos Garatea en «Escritura y conquista: fragmentos para una historia del español americano», y lo hace analizando las reflexiones que el Inca Garcilaso y Guamán Poma de Ayala dedicaron respectivamente en sus obras Comentarios reales (1609) y Primer nueva Crónica y Buen Gobierno (1615). En efecto, la conquista de América -señala Garateafue también una "conquista textual», una difusión de modelos y tradiciones textuales desconocidas hasta entonces por la población nativa y que esta, según los distintos niveles de competencia en la nueva lengua y en su escritura -que Garatea perfila en toda su complejidad en el apartado 1 «La llegada de la escritura»-, se vio forzada a adoptar progresivamente, pues el discurso escrito articulaba las nuevas formas de organización política, social y cultural. Surgen así complicadas relaciones entre la oralidad quechua y la escritura española y los valores asociados a estas, de las que el Inca Garcilaso y Guamán Poma de Ayala dejaron constancia en sus obras. El primero, reivindicando - no sin amargura por la ausencia de fijación escrita que pudiera dar fe de lo narrado- la verdad de la grandeza histórica del imperio inca transmitida tradicionalmente por los amautas (historiadores) y haravicus (poetas) quechuas, y que él, como conocedor experto de ambas lenguas, puede ahora desplegar ante los europeos gracias al dominio de los modelos historiográficos propios de la escritura. El segundo, en su combinación e interferencia de modelos lingüísticos y textuales escritos castellanos y orales quechuas, dando fe de la convivencia -complicada, pero enriquecedora, del contacto de lenguas y culturas- y resaltando la importancia del dominio del español y su escritura para los indios quechuas -a pesar de las trabas interesadas de colonos y misioneros- como único medio para participar plenamente en la nueva sociedad que se estaba creando.

Por su parte, Elena Méndez García de Paredes se ocupa de desentrañar el verismo y la verosimilitud de la técnica constructiva de los diálogos de $L a$ colmena de Camilo José Cela y de explicar así cómo funciona dicha técnica -constituyente fundamental del «objetivismo documental» de la obra- que rompe radicalmente con los cánones retóricos de los diálogos literarios hasta la época -lo que fue percibido y criticado en su momento- no solo por su acercamiento a las estructuras discursivas y lingüísticas de la conversación cotidiana, sino a su modo de inserción en el relato, con intervenciones mínimas y peculiares del narrador, y a su función en el desarrollo narrativo. Méndez García de Paredes comienza por describir la naturaleza inherentemente intertextual y autorreferencial de la oralidad conversacional en la escritura literaria, para pasar luego a analizar detenidamente, a partir de las herramientas que proporcionan, de un lado, el modelo de variación concepcional vinculado al continuum inmediatez y distancia comunicativas y, de otro, el análisis de la conversación, cómo maneja Cela tres componentes de la interacción conversacional: la gestión de los temas, la estructura secuencial de la interacción y el modelo de lengua empleado. 
Con respecto a los temas, la autora saca a la luz cómo, a pesar de las restricciones que imponen a su selección en toda obra literaria la coherencia y pertinencia narrativas, consigue Cela acercarse tanto al libre fluir de los temas en las interacciones conversacionales como a su desarrollo colaborativo entre los participantes-personajes, y cómo, en ambos casos, se adecua pragmáticamente al contexto situacional y a las identidades sociales, a las relaciones interpersonales y a las intenciones de los personajes. En cuanto al análisis de la construcción de los diálogos de La colmena, Elena Méndez analiza tanto su disposición «externa»: alternancia de turnos breves, introducidos con un formato gráfico de guiones y apenas intervenciones del narrador, que trata de reflejar icónicamente la organización secuencial de la interacción conversacional, como su desarrollo discursivo, pues en él son predominantes actos de habla y marcadores discursivos enfocadores y apeladores de la alteridad, con los que se construye una verdadera interlocución e inter-acción entre los personajes. Por último, Méndez García de Paredes describe la «coloquialidad» lingüística de estas interacciones, no limitándose a la descripción del uso de determinados elementos léxicos y gramaticales marcados diatópica, diastrática o diafásicamente, sino centrándose en las formas de construcción sintáctica propias de los enunciados vinculados a la ausencia de planificación característica de la inmediatez comunicativa: tematizaciones, sintaxis agregativa, repeticiones, paralelismos, etc.

A la luz de lo expuesto, parece evidente que los artículos que componen este volumen muestran las diferentes perspectivas y objetivos con que se puede -y debe- abordar el estudio de la «oralidad fingida» $\mathrm{o}$ «mímesis de la oralidad» en los textos literarios, y con ello, la importancia de su estudio. En el plano diacrónico, los intereses abarcan desde la pretensión de recuperar, por muy incompletamente que sea, aspectos de la oralidad conversacional del pasado, remoto o cercano, hasta el estudio de la progresiva evolución de su construcción literaria pasando por las relaciones históricas entre discurso escrito y discurso hablado (todos ellos temas explícitamente planteados y estudiados por José Jesús de Bustos Tovar). En el plano sincrónico, además de la caracterización de estilos e intenciones de novelistas y dramaturgos, los artículos comprendidos en este número monográfico abordan cuestiones cruciales para el tratamiento de la recreación literaria de la oralidad, como la de las peculiaridades que presenta y las limitaciones a que debe plegarse todo intento de oralidad fingida, la de la necesidad de tener en cuenta los procedimientos específicos de construcción del discurso escrit-oral en la literatura para el análisis lingüístico, pragmático y discursivo de las traducciones y la de la relevancia que el estudio de la «trasposición» de lo oral a lo escrito tiene para la puesta a prueba de los modelos, conceptos y categorías con los que en las últimas décadas se ha procedido a la aprehensión de la variación concepcional. 